\title{
Fusion meets the realities of global politics
}

Paris. Scientific and engineering goals must be tailored to political needs if international collaborations on 'big science' projects are to work. That seems to be one message emerging as the dust settles on a recent management crisis at the International Thermonuclear Experimental Reactor (ITER) project, which last month cost the director, Paul-Henri Rebut, his job.

ITER, formally launched in 1988, was planned from the outset as a collaboration between Europe, the United States, Russia and Japan, aimed at demonstrating the feasibility of controlled nuclear fusion (see Nature 358, 269; 1992). It is intended to produce a design for a huge tokamak reactor capable of sustaining fusion in a magnetically confined deuterium-tritium plasma for 1,000 seconds, while demonstrating that the process is safe.

A decision whether to extend the ITER agreement to include construction will be made before 1998 - the current engineering design phase commits the partners only to producing sufficiently detailed designs by then to allow construction "either alone or together". If the reactor is eventually built, it may be followed by a commercial prototype around 2025 .

So far, the \$5.6-billion ITER collaboration has been widely considered a model of how to manage a 'big science' project. But after Rebut was dismissed by the ITER council - which is made up of representatives of the four participating blocs - he complained that the "diverse priorities of the national programmes will not result in a coherent engineering design".

In particular, Rebut argued that the ITER agreement needed to be restructured to give his central team the "responsibility and authority" he felt was needed to do the job properly. One observer, for example, says that Rebut, who had little power to allocate funds and research, feared that design by a quadripartite committee would result in a "dog's breakfast".

Rebut said that during his previous experience as the widely-respected head of the Joint European Torus (JET), at Culham in the United Kingdom, the "project made the key decisions, and the national programmes played a supportive role". He has argued that: "The same must also be true for ITER."

But politics rather than efficiency seems to have determined the division of ITER research among 'co-centres' in Garching in Germany, Naka in Japan, and San Diego in the United States. Some claim that this distribution was the price of securing collaboration, accepting that, as ITER is a paper design and not an engineering project, a single site is not strictly essential at present.

Fusion supporters are divided over the legitimacy of Rebut's complaints. JET's internal newsletter JET News implicitly sup- ported his call for a restructuring, and speculated that he might have been fired for not "suffering fools gladly". It described Rebut as a "brilliant engineer/physicist and a decisive leader", who would "undoubtedly be a hard act to follow".

Others argue, however, that Rebut failed to appreciate the differences between managing JET and coordinating ITER. One official from the European Union (EU) fusion programme says, for example, that Rebut wanted to design a much more ambitious reactor than that originally agreed to by the four partners.

The official claims that Rebut wanted ITER to demonstrate that fusion was both technologically and economically feasible. He says that Rebut's design would have pushed ITER well over its agreed budget, and required technology that does not yet exist - for example, reactor blankets that could breed further tritium to reintroduce as fuel. (Rebut is currently on holiday, and could not be contacted for comment.)

A management review carried out by the ITER council concluded in May that Rebut's management of the programme was too hands-on. "Rebut ran ITER as a oneman show", thus denying researchers in the four blocs the participation in ITER that they had paid for says one EU official. "Rebut thought ITER was a blank cheque for his own dreams."

Robert Aymar, Rebut's successor, says that Rebut failed to appreciate that he did not, and could not, have the same degree of control over ITER as he had over JET. The latter is four-fifths funded by Euratom (the

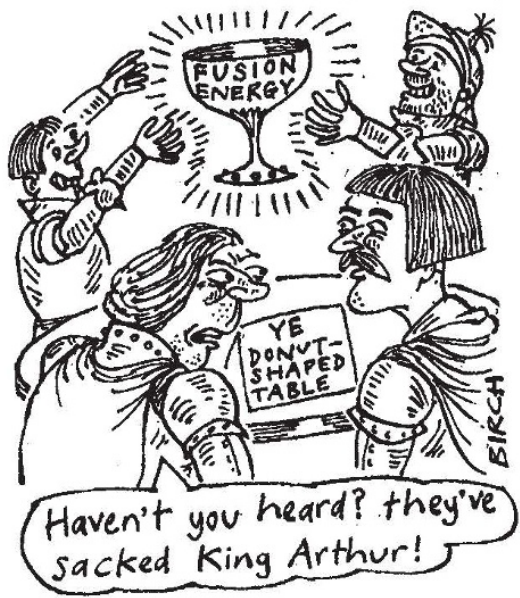

European Atomic Energy Community) whereas ITER has to accommodate the needs of the programmes of four powerful blocs.

Aymar agrees that this quadripartite structure "cannot be as effective as a small team". But he insists that such structures are "inevitable" in international technological collaborations.

The job of the ITER director, Aymar says, is to make the best of this situation by shaping the various contributions of the projects and industries of the participating countries into a coherent "single project".

One difficulty in persuading groups to cooperate within ITER, says Aymar, is that it is a paper design project. This means that laboratories often prefer to further their own projects, as they can get more immediate scientific results from their own smaller but operational equipment.

Aymar says his main aim as director will be to ensure that ITER is actually built. One EU official says that if it is not, the partners - who together spend some $\$ 1.5$ billion annually on fusion research — "will say fusion is dead". Indeed, a bill passed in the US Senate already proposes that if ITER fails, the United States should reduce fusion funding from $\$ 344$ million to $\$ 50$ million.

The four blocs are collaborating on ITER only because none of them - with the possible exception of Japan - is sufficiently convinced of the technological and economic feasibility of fusion to provide the heavy development costs on its own. Although some EU officials say that Europe says it would go it alone if ITER failed, others are sceptical.

To ensure ITER's success, Aymar is prepared to be pragmatic. He says, for example, that he will settle for conservative choices in the design of ITER to keep the projects within its current budget estimates, "even if these are not the best for fusion in the long term".

Some sponsoring governments anticipate that, when a site for the reactor is finally chosen, the national blocs not selected may lose interest and fall back on their national programmes.

To avoid this happening, Aymar says the decision on whether to construct ITER, how much each country will pay, and where the reactor will be sited, will be negotiated within a single package, sometime between 1996 and 1998

One side-effect of the management crisis at ITER has been to reopen public debate on the wisdom of fusion research. But whereas the publicity given to reports of cold fusion in 1989 unexpectedly increased awareness and support for hot fusion, the latest publicity has reawakened the critics.

The European Parliament, for example, which has long been sceptical of claims that fusion can offer limitless cheap, clean energy, recently nominated a critic of fusion research, Detlev Samland (Social Democrat, Germany), to head its powerful budget committee.

With pressure growing on the EU to spend more on research areas of immediate economic relevance, the ECU200 million spent annually on fusion research may become an increasingly attractive target for cuts.

Declan Butler 